\title{
Sporotrichosis in renal transplant patients
}

\author{
Paulo Gewehr MD, Bruno Jung MD, Valerio Aquino PhD, Roberto C Manfro MD PhD, \\ Fábio Spuldaro MD, Regis G Rosa MD, Luciano Z Goldani MD PhD
}

P Gewehr, B Jung, V Aquino, et al. Sporotrichosis in renal transplant patients. Can J Infect Dis Med Microbiol 2013;24(2):e47-e49.

The current report describes two renal transplant recipients who presented with sporotrichosis. In addition, the authors review the general aspects of sporotrichosis in renal transplant recipients reported in the literature. Sporotrichosis is a rare fungal infection in transplant patients and has been reported primarily in renal transplant recipients not treated with antifungal prophylaxis. Extracutaneous forms of sporotrichosis without skin manifestations and no previous history of traumatic injuries have been described in such patients and are difficult to diagnose. Renal transplant recipients with sporotrichosis described in the present report were successfully treated with antifungal therapy including amphotericin B deoxycholate, lipid amphotericin B formulations, fluconazole and itraconazole.

Key Words: Invasive mycosis; Renal transplant; Sporothrix schenckii; Sporotrichosis

Sporothrix schenckii is the etiological agent of sporotrichosis, a $\int$ chronic fungal infection that most frequently affects cutaneous and subcutaneous tissues and adjacent lymphatics (1). Sporotrichosis has been described on five continents, with a higher prevalence in tropical and temperate zones. Infection generally occurs following traumatic inoculation with soil, plants and organic matter contaminated with the fungus. The fungus is also occasionally inhaled, causing pneumonitis that often cavitates. S schenckii can disseminate hematogenously to the bones, central nervous system, liver, spleen, gastrointestinal tract, kidneys and eyes in a normal host or cause disseminated multifocal disease in an immunocompromised individual $(1,2)$. Zoonotic transmission has been increasing significantly, with a recent report of an epidemic outbreak with zoonotic transmission by infected cats in Brazil (1).

Fungal infections, including candidiasis, cryptococcosis and aspergillosis, occur in $9 \%$ to $14 \%$ of patients following a renal transplant (3). Sporotrichosis, however, is rare in renal transplant recipients. We report two renal transplant recipients presenting with sporotrichosis. In addition, we review the general aspects of sporotrichosis in renal transplant recipients reported in the medical literature.

\section{CASE PRESENTATIONS}

Case 1

A 48-year-old female renal transplant recipient was admitted to hospital in September 2011 following the appearance of papular lesions on her left hand and right ear. The patient was a state employee and lived in the southern region of Brazil. Four years before admission, the patient received a renal transplant from a deceased donor. No rejection episodes occurred during this time period. Two months before the appearance of the skin lesions, she experienced a minor injury to the head and left hand resulting from a car accident. The patient was taking immunosuppressive agents including mycophenolate mofetil ( $2 \mathrm{~g} /$ day $)$, tacrolimus ( $3 \mathrm{mg} /$ day $)$ and prednisone $(5 \mathrm{mg} /$ day $)$, and urinary tract infection prophylaxis with trimethoprim-sulfamethoxazole. A physical

\section{Une sporotrichose chez des greffés du rein}

Le présent rapport décrit deux greffés du rein qui ont présenté une sporotrichose. De plus, les auteurs ont examiné les aspects généraux de la sporotrichose chez des greffés du rein signalés dans les publications. La sporotrichose, une infection fongique rare chez les greffés, s'observe surtout chez des greffés du rein qui ne reçoivent pas de prophylaxie antifongique. Des formes extracutanées de sporotrichose, sans manifestations cutanées et sans antécédents de lésions traumatiques, ont été décrites chez ces patients, mais elles sont difficiles à diagnostiquer. Les greffés du rein atteints de sporotrichose décrits dans le présent rapport ont été traités avec succès à l'aide d'un antifongique, y compris le désoxycholated d'amphotéricine $\mathrm{B}$, les formulations lipidiques d'amphotéricine B, le fluconazole et l'itraconazole.

\begin{abstract}
examination demonstrated that the patient was alert, oriented and in no acute distress. Her temperature was $36.9^{\circ} \mathrm{C}$, her heart rate was 81 beats/min and her respiratory rate was 16 breaths/min. Chest and abdominal examinations were normal. A cutaneous examination revealed two ulcerative and painful plaques on the dorsal aspect of her left hand with slight fluctuation in response to palpation (Figure 1A). In addition, the patient presented erythematous, crusted, exudative lesions on her right ear and preauricular region (Figure 1B). She was initially treated with antibiotics for a bacterial skin infection without lesion improvement. Her blood cultures were negative. Cultures of lesion biopsy specimens from her left hand grew a fungus belonging to Sporothrix species. A mycological examination included direct microscopy with $4 \%$ sodium hydroxide and seeding onto Sabouraud dextrose agar at $25^{\circ} \mathrm{C}$. The isolated fungi were studied for macroscopic and microscopic morphology on dextrose agar medium at $25^{\circ} \mathrm{C}$ and conversion of Sporothrix species to the yeast form was observed on brain heart infusion agar medium at $37^{\circ} \mathrm{C}$. The patient was successfully treated with intravenous amphotericin B lipid complex $(5 \mathrm{mg} / \mathrm{kg} / \mathrm{day}$ for 10 days) followed with oral itraconazole at $400 \mathrm{mg} /$ day for eight weeks. Her renal function was stable and preserved (serum creatinine $79.56 \mu \mathrm{mol} / \mathrm{L}$ ). The lesions on her right ear and left hand regressed, and the patient was maintained on suppression therapy with oral itraconazole at $200 \mathrm{mg} /$ day.
\end{abstract}

\section{Case 2}

A 53-year-old male renal transplant recipient was admitted to hospital in August 2009, because of a 10-day history of generalized weakness, joint pain, and disseminated nodular and ulcerated lesions involving the upper and lower extremities and trunk. The patient was a retired veterinarian who lived on a farm in the southern region of Brazil. He denied any history of contact with cats or other animals, or recent trauma. Eight years before admission, the patient received a renal transplant from a living unrelated donor. After renal transplant failure, the patient received a second renal transplant from a deceased donor in July 2009. The patient was taking immunosuppressive 

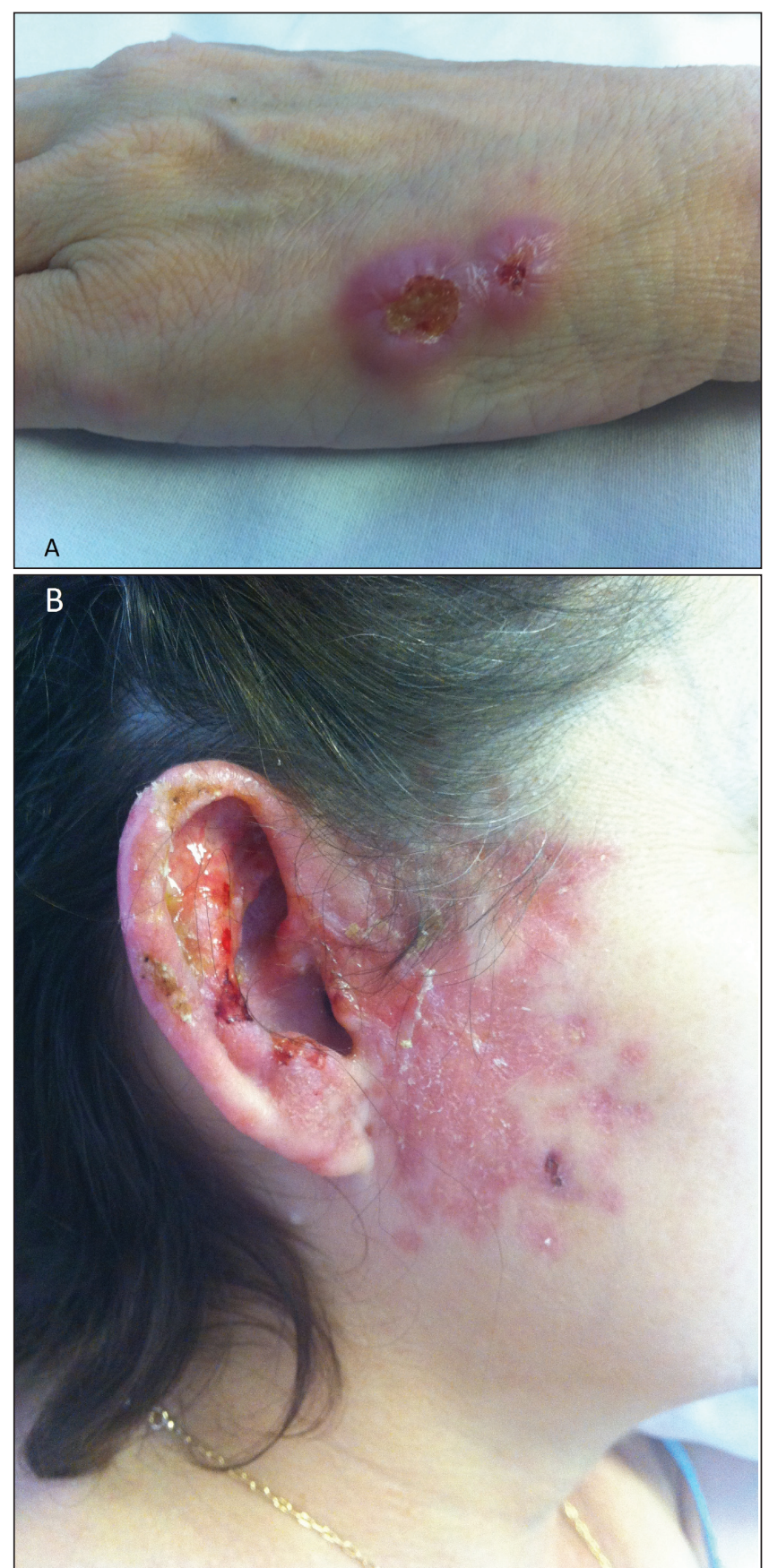

Figure 1) A renal transplant recipient with sporotrichosis. Note the ulcerative and painful plaques on the dorsal aspect of the hand (A) and crusted, exudative lesions on the right ear and preauricular region (B)

agents including mycophenolate mofetil (2 g/day), tacrolimus ( $3 \mathrm{mg} /$ day) and prednisone $(5 \mathrm{mg} /$ day $)$, and prophylaxis for urinary tract infections and cytomegalovirus infection with trimethoprimsulfamethoxazole and oral ganciclovir (1 g every $8 \mathrm{~h}$ ). A physical examination demonstrated that the patient was alert, oriented and in no acute distress. His body temperature was $36.8^{\circ} \mathrm{C}$, his heart rate was 90 beats/min and his respiratory rate was 19 breaths/min. A cutaneous examination revealed subcutaneous nodules on the limbs and trunk $1 \mathrm{~cm}$ to $2 \mathrm{~cm}$ in size, firm, tender and erythematous, with occasional necrotic centres and drainage of purulent discharge (not shown). His right knee and wrist were swollen and warm, and he experienced pain on palpation. Chest and abdominal examinations were normal.
His blood cultures were negative. Cultures of skin biopsy specimens grew a fungus belonging to Sporothrix species as described in case 1 . A histopathological examination of the skin biopsies revealed a dermal granulomatous inflammatory process with some foci of necrosis. Fungal structures and cigar-shaped bodies compatible with Sporothrix species were visualized using periodic acid-Schiff and silver stains. His left wrist was aspirated and $1 \mathrm{~mL}$ of yellow fluid was removed. A culture of the aspirated fluid grew Sporothrix species. An x-ray of the wrist bones did not show any evidence of osteomyelitis. Treatment with oral itraconazole at $400 \mathrm{mg} /$ day led to the disappearance of skin lesions and the regression of the articular inflammatory process within 90 days. The patient was subsequently maintained on suppression therapy with itraconazole at $200 \mathrm{mg} /$ day. In November 2010, he complained of pain and swelling in his right wrist and elbow. A culture of aspirate from his right wrist grew Sporothrix species. He was treated successfully with intravenous amphotericin B lipid complex ( $5 \mathrm{mg} / \mathrm{kg} /$ day for 28 days) for the recurrent sporotrichosis. Because the patient relapsed during itraconazole therapy, he was maintained on suppressive therapy with fluconazole (600 mg/day).

\section{DISCUSSION}

Renal transplant recipients are at increased risk for infection, including cutaneous infections because of the effects of immunosuppressive therapy (4). Renal transplantation is associated with the lowest incidence of fungal infection of all solid-organ transplantation procedures (3). Fungi account for approximately $6 \%$ of all infections in renal transplant recipients, and prophylaxis in kidney transplant recipients should be limited to those with candiduria. Candida species, Aspergillus species and Cryptococcus neoformans are the most frequently isolated, although other types of fungal infection have also been described. Sporotrichosis is rarely described in transplant patients and has been described almost exclusively in renal transplant recipients. The patient described in case 1 presented with a fixed cutaneous form of the disease, while the patient in case 2 presented a disseminated form of sporotrichosis, which could be related to the different degrees of immunosuppression in each patient. Unfortunately, we were not able to speciate our Sporothrix isolates. It has been demonstrated that the geographical amplitude of occurrence and the pathogenicity vary within this complex of species. Other studies have emphasized the importance of species differentiation for choosing the optimal antifungal therapy $(5,6)$.

We identified four cases of sporotrichosis in renal transplant recipients reported in the medical literature (MEDLINE) to date (Table 1) (7-10). In contrast to our patients, skin manifestations were not present in three of four case reports in the literature. Unusual forms of sporotrichosis, including meningitis, pyelonephritis and nasopharyngeal masses, were described in those patients. In addition, only one patient in previously reported cases and one in the the present report, had a history of an injury before the development of sporotrichosis. The time from transplantation to the development of sporotrichosis varied from one month to four years. Similar to our patients, none of the renal transplant recipients with sporotrichosis received antifungal prophylaxis. Surgical complications and graft rejection resulting in the intensification of immunosuppressive therapy were present in most of the cases.

There are no clinical trials to guide therapy for disseminated sporotrichosis in immunosuppressed hosts. Renal transplant recipients with sporotrichosis, including our patients, were successfully treated with antifungal therapy including amphotericin B deoxycholate, lipid amphotericin B formulations and itraconazole. Antifungal agents should be given to complete a total of at least 12 months of induction therapy in patients with disseminated sporotrichosis. Life-long suppressive therapy with itraconazole (200 $\mathrm{mg}$ daily) is required if immunosuppression cannot be reversed. Serum levels of calcineurin inhibitors, such as tacrolimus and cyclosporine, significantly increase after initiation of itraconazole. Dose adjustment of calcineurin 
TABLE 1

Characteristics of renal transplant patients with sporotrichosis

\begin{tabular}{|c|c|c|c|c|c|c|}
\hline $\begin{array}{l}\text { Author (reference), } \\
\text { year }\end{array}$ & $\begin{array}{l}\text { Age, yearsl } \\
\text { sex }\end{array}$ & Type of renal transplant & Clinical manifestations (time after transplant) & $\begin{array}{l}\text { History of } \\
\text { trauma }\end{array}$ & Treatment & Outcome \\
\hline Caroti et al (7), 2010 & 59/male & Unknown & Erythematous papular lesion on the left leg (NA) & Yes & FLZ & Alive \\
\hline Rao et al (8), 2002 & 49/female & Deceased donor & Nasopharyngeal mass (six months) & No & None & Death \\
\hline Agarwal et al (9), 1994 & 23/male & Live related donor & Pyelonephritis (nine months) & No & None & Death \\
\hline Gullberg et al (10), 1987 & 50/male & Deceased donor & Arthritis, meningitis (four years) & Unknown & AMB-d & Alive \\
\hline Present study & 48/female & Deceased donor & $\begin{array}{l}\text { Plaques and ulcers on the hand and ear } \\
\text { (nine months) }\end{array}$ & Yes & AMB-L; ITZ & Alive \\
\hline Present study & 53/male & $\begin{array}{l}\text { Deceased and live } \\
\text { unrelated donors }\end{array}$ & $\begin{array}{l}\text { Arthritis, draining and necrotic subcutaneous } \\
\text { nodules in the limbs and trunk (one month) }\end{array}$ & No & AMB-L; ITZ; FLZ & Alive \\
\hline
\end{tabular}

AMB-d Amphotericin B deoxycholate; AMB-L Amphotericin lipid complex; FLZ Fluconazole; ITZ Itraconazole; NA Not available

inhibitors on initiating itraconazole should be guided by close monitoring of serum concentrations. In a recent study, Gutierrez-Galhardo et al (11) reported that amphotericin B, itraconazole, posaconazole, ravuconazole and terbinafine were active in vitro against mycelia and yeast phases of Sporothrix but minimum inhibitory concentrations values for the mycelial phase were significantly higher. Fluconazole and voriconazole were inactive in vitro against both phases. There are no studies supporting the use of posaconazole, ravuconazole and terbinafine for treating disseminated sporotrichosis.

\section{REFERENCES}

1. Barros MB, de Almeida Paes R, Schubach AO. Sporothrix schenckii and sporotrichosis. Clin Microbiol Rev 2011;24:633-54.

2. Bustamante B, Campos PE. Endemic sporotrichosis. Curr Opin Infect Dis 2001;14:145-9.

3. Badiee P, Alborzi A. Invasive fungal infections in renal transplant recipients. Exp Clin Transplant 2011;9:355-62.

4. Silva M Jr, Marra AR, Pereira CA, et al. Bloodstream infection after kidney transplantation: Epidemiology, microbiology, associated risk factors, and outcome. Transplantation 2010;90:581-7.

5. Silva-Vergara ML, de Camargo ZP, Silva PF, et al. Disseminated Sporothrix brasiliensis infection with endocardial and ocular involvement in an HIV-infected patient. Am J Trop Med Hyg 2012;86:477-80.

6. de Oliveira MM, de Almeida-Paes R, de Medeiros Muniz M, et al. Sporotrichosis caused by Sporothrix globosa in Rio De Janeiro, Brazil: Case report. Mycopathologia 2010;169:359-63.

7. Caroti L, Zanazzi M, Rogasi P, et al. Subcutaneous nodules and infectious complications in renal allograft recipients. Transplant Proc 2010;42:1146-7.

\section{SUMMARY}

Sporotrichosis is a rare fungal infection in transplant recipients and has generally been described in renal transplant recipients not treated with antifungal prophylaxis. Extracutaneous forms without skin manifestations and no history of traumatic injuries have been reported in some patients and are difficult to diagnose. Due to the adverse effects related to amphotericin B deoxycholate, lipid amphotericin B formulations and itraconazole are currently the optimal treatments for renal transplant recipients with sporotrichosis $(12,13)$.

8. Rao KH, Jha R, Narayan G, et al. Opportunistic infections following renal transplantation Indian J Med Microbiol 2002;20:47-9.

9. Agarwal SK, Tiwari SC, Dash SC, et al. Urinary sporotrichosis in a renal allograft recipient. Nephron 1994;66:485.

10. Gullberg RM, Quintanilla A, Levin ML, et al. Sporotrichosis: Recurrent cutaneous, articular, and central nervous system infection in a renal transplant recipient. Rev Infect Dis 1987;9:369-75.

11. Gutierrez-Galhardo MC, Zancopé-Oliveira RM, Monzón A, Rodriguez-Tudela JL, Cuenca-Estrella M. Antifungal susceptibility profile in vitro of Sporothrix schenckii in two growth phases and by two methods: Microdilution and E-test. Mycoses 2010;53:227-31.

12. Kauffman CA, Bustamante B, Chapman SW, et al; Infectious Diseases Society of America. Clinical practice guidelines for the management of sporotrichosis: 2007 update by the Infectious Diseases Society of America. Clin Infect Dis 2007;45:1255-65.

13. de Lima Barros MB, Schubach AO, de Vasconcellos Carvalhaes de Oliveira R, et al. Treatment of cutaneous sporotrichosis with itraconazole - study of 645 patients. Clin Infect Dis 2011;52:e200-e206. 


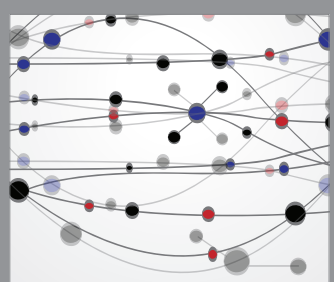

The Scientific World Journal
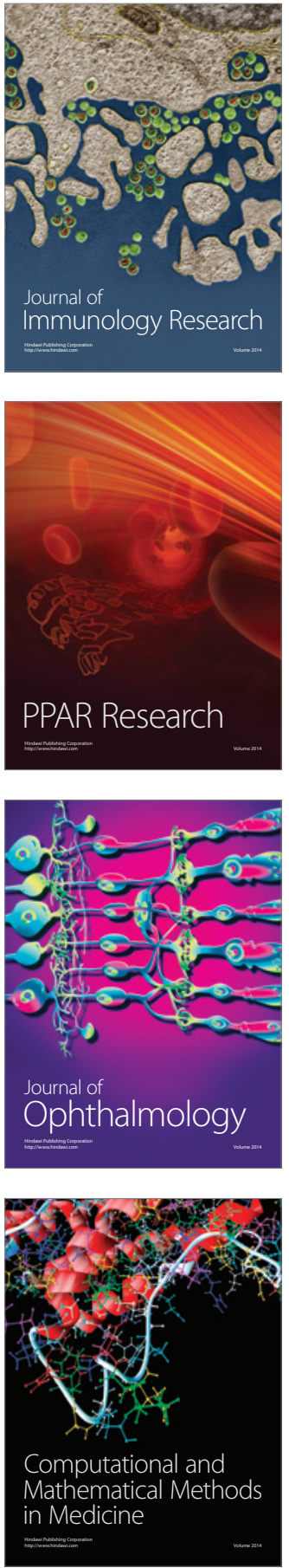

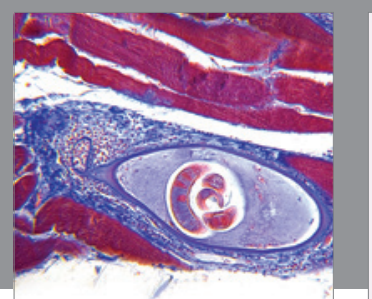

Gastroenterology Research and Practice

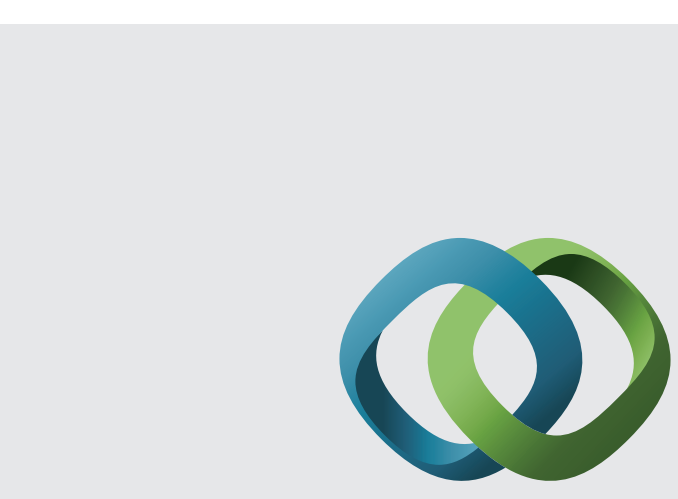

\section{Hindawi}

Submit your manuscripts at

http://www.hindawi.com
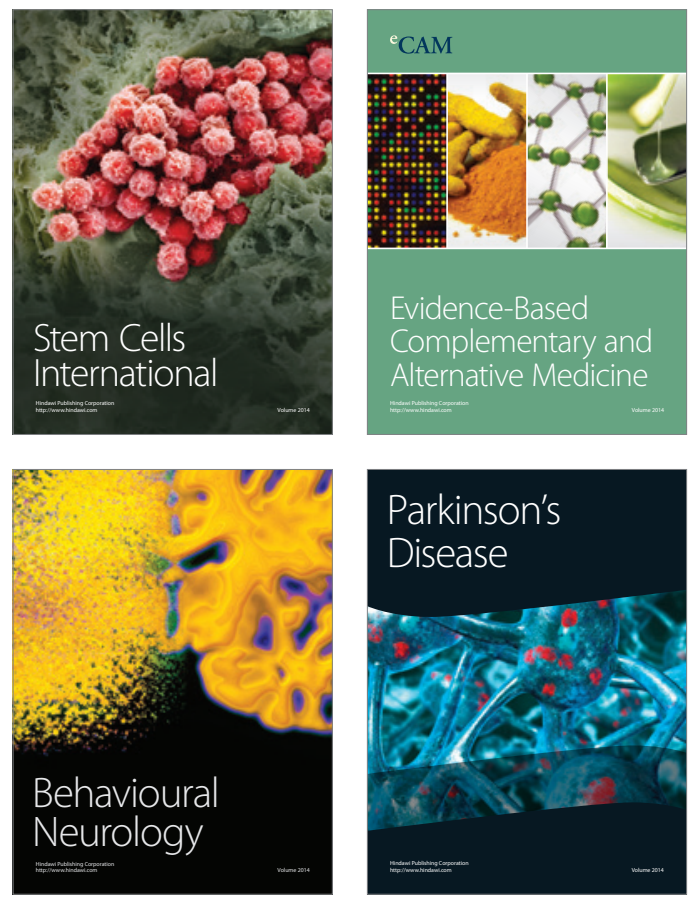
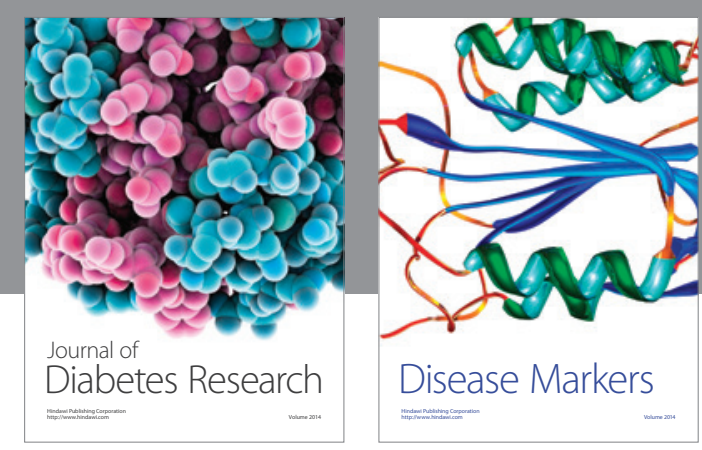

Disease Markers
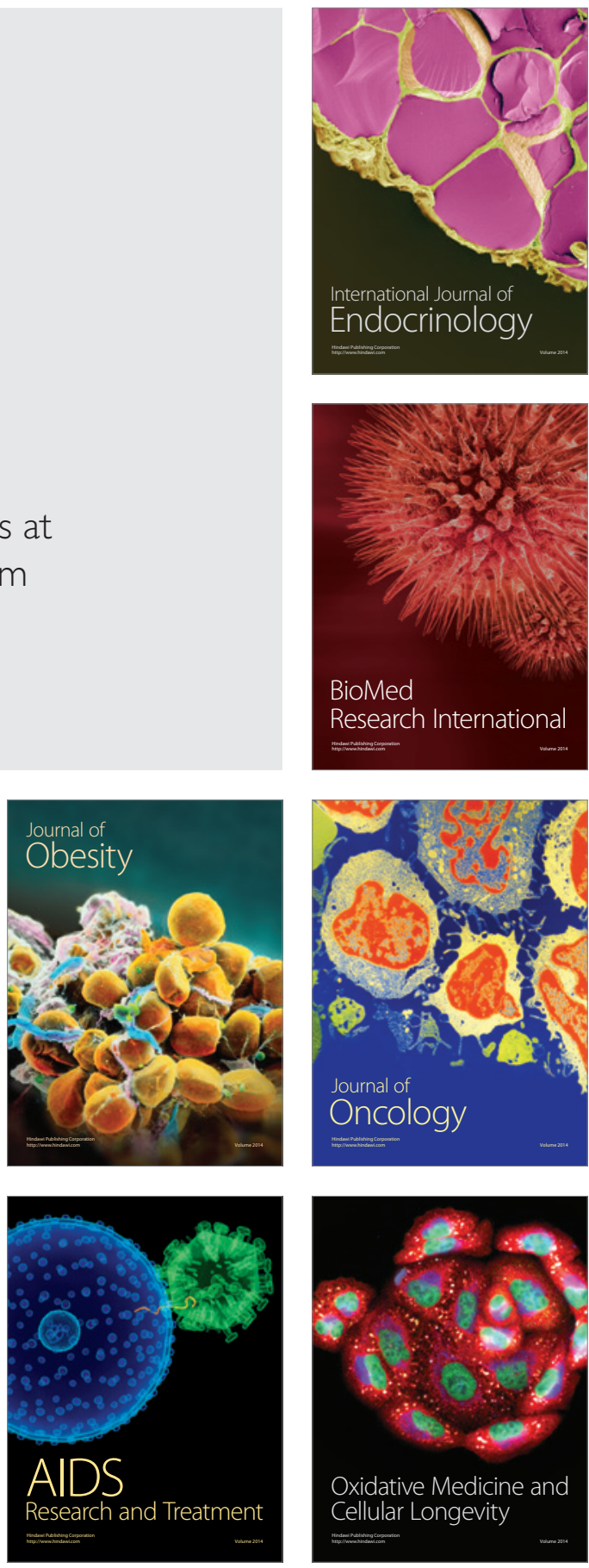